\title{
Application of fracture energy for the assessment of frost degradation of high-strength concretes
}

\author{
Sylwia Anna Borowska ${ }^{1}$, Marta Kosior-Kazberuk ${ }^{2}$ \\ ${ }^{1}$ Department of Building Structures; Faculty of Civil Engineering and Environmental Sciences; \\ Bialystok University of Technology; \\ 45 E Wiejska St., 15-351 Bialystok, Poland; \\ s.borowska@doktoranci.pb.edu.pl (iD 0000-0003-2100-2673 \\ 2 Department of Building Structures; Faculty of Civil Engineering and Environmental Sciences; \\ Bialystok University of Technology; \\ 45 E Wiejska St., 15-351 Bialystok, Poland; \\ m.kosior@pb.edu.pl (DD000-0001-8171-2242
}

\begin{abstract}
Knowledge of fracture mechanics parameters can help for a more accurate assessment of frost degradation of high-strength concrete. High strength concretes, despite the tight structure, are characterized by increased brittleness. Cracks in the concrete structure are places of accumulation of significant stresses. Additional stresses resulting from cyclic freeze/thaw stimulate the material destruction processes. The basic strength parameters of concrete do not take into account structural defects of the material and do not give a complete description of susceptibility to damage caused by, e.g., frost degradation. This study aimed to determine the relationship between frost degradation of high-strength concretes and changes in the value of their fracture energy associated with the initiation of cracking after 150, 250, 350 and 450 freeze/thaw cycles. The research was carried out using $100 \times 100 \times 400 \mathrm{~mm}$ samples, with a pre-initiated $30 \mathrm{~mm}$ deep notch. The I load model under a three-point bending test was used, based on the procedure recommended by RILEM. Concrete with a compressive strength of $90 \mathrm{MPa}$ with steel fibres and a mixture of steel and basalt fibers was tested. The obtained results allow for the evaluation of frost degradation using fracture energy $G_{\mathrm{F}}$ and critical crack tip opening displacement $C T O D_{\mathrm{c}}$.
\end{abstract}

Keywords: fracture energy, frost resistance, high strength concrete, fiber, fiber reinforced concrete

\section{Introduction}

Internal material defects associated with manufacturing inaccuracies and loss of durability are avoided in standard calculations and the dimensioning of components. Despite the use of safety factors, the analysis results are random. The basic information about the concrete 
is assumed on the basis of dimensions, material data and the standardization of its parameter (compressive strength, longitudinal modulus of elasticity, tensile strength). Even minor defects in the initial period of the structure's use, together with the destructive impact of the external environment, lead to the progress of degradation and loss of durability. A more detailed analysis of the effect of material defects on the loss of HSC durability as a result of cyclic freeze/thaw is possible by analyzing changes in the concrete fracture mechanics parameters [1]. Modern material engineering aims to ensure the best possible durability of concrete structures. At the same time, it aims to minimize the cross-sectional dimensions of the structure and comply with the conditions of sustainable development. During the design process, it is the following the rational use of building materials that ensures high insulation of buildings and minor material losses. For this purpose, structural elements are increasingly frequently made of high-strength concretes, characterized by a tighter structure and more favourable mechanical parameters than normal concretes, which allows to reduce the consumption of materials. The use of HSC as a material for vertical structural elements leads to larger usable spaces. High strength concrete facade elements are much thinner and lighter [2].

To ensure the high durability of external concrete structures, their frost resistance should be guaranteed. Cyclical freeze/thaw leads to the accumulation of significant internal stresses and, as a consequence, to degradation of the concrete structure. The degree of damage caused by freeze/thaw depends primarily on the size and distribution of internal pores in the concrete, as well as the presence of discontinuities and defects. The larger and less frequently the pores are spaced, the more frozen water will accumulate in them. It can create more tensile stress when the ice forms and then defrosts concrete components (aggregates, cement, water), which vary in thermal properties [3]. However, if the structure of the material is compact, with no internal defects, then there is less chance of freezing water accumulating in certain areas. By reducing the water-cement ratio and using various additives to increase the strength of the concrete, it is possible to achieve a more airtight HSC structure compared to standard concrete. However, high strength concretes are prone to sudden cracking due to their quasi-brittle behaviour, which in combination with internal damage developing as a result of external factors may lead to a loss of load-bearing capacity of the structure [4]. Changing the material characteristics of high-strength concrete from quasi-brittle to quasi-plastic is possible by adding fibers with high tensile strength (steel, basalt) to the concrete mix [5]. Fibers in reinforced concrete members can also completely or partially replace standard reinforcement with steel rods. This change contributes to a reduction in production costs, material consumption in the bar plant, pollution emissions, and overall construction costs. The right amount of steel fibers added to the concrete matrix, correctly distributed, increases the bending tensile strength [6].

Degradation of high-strength concretes as a result of cyclic freeze/thaw is revealed by the development of discontinuities initially occurring in the concrete element. Due to the complex microstructure of the concrete, the strength properties are not sufficient to describe the behaviour of the material. The highest stress concentration is associated with the tip of the gap, discontinuity, or crack. A coherent model representing the destruction of concrete can be shown by the fracture energy changes. It is the basic parameter of fracture mechanics, describing the susceptibility of a material to crack propagation, as the amount of energy absorbed during the crack formation in the material subjected to degradation. The use of fracture mechanics in the analysis of the structure can lead to avoiding many design errors and a better understanding of the material behaviour. The higher the fracture energy, the material is less susceptible to failure [7]. 
This work aimed to present the relationship between the degree of frost degradation of high-strength concretes with the addition of steel and mixed steel and basalt fibers and without fibers, described by the durability factor $D F$ [8], and changes in fracture energy values $G_{\mathrm{F}}$ after $150,250,350$ and 450 freeze/thaw cycles. Based on the load-deflection relationship function, the focus is on the area related to crack initiation and on the cover area. The tests were carried out on the basis of RILEM [9] recommendation under a three-point bending test. Changes in the HSC brittleness parameter due to cyclic freeze/thaw were also determined [10].

\section{Experimental program}

\subsection{Materials and sample preparation}

In the study, the specimens with dimensions of $100 \mathrm{~mm} \times 100 \mathrm{~mm} \times 400 \mathrm{~mm}$ were used, according to the method of determining the parameters of fracture mechanics recommended by Jenq Y. S. and Shah [10]. The concrete was made of Portland cement CEM I $42.5 R\left(440.5 \mathrm{~kg} / \mathrm{m}^{3}\right)$. Gravel limited to $11 \mathrm{~mm}$ and river sand $0-2 \mathrm{~mm}$ was applied. The content of the $0 / 2 \mathrm{~mm}$ aggregate fraction in the mixture was $346 \mathrm{~kg} / \mathrm{m}^{3}$ ( $18 \%$ by mass), the $2 / 5 \mathrm{~mm}$ fraction $-372 \mathrm{~kg} / \mathrm{m}^{3}$ (22\% by mass), and the $5 / 11 \mathrm{~mm}$ fraction $-1112 \mathrm{~kg} / \mathrm{m}^{3}(60 \%$ by mass). A superplasticizer was used in the amount of $1.65 \%$ of the binder mix. Concrete with compressive strength of $90 \mathrm{MPa}$ was tested. A constant water-binder ratio w/s= $=0.31$ was provided. The consistency of fresh concrete by the slump test was determined as S3. Three categories of concrete were prepared: MB1 - high strength concrete without fibers, MB2 - high strength concrete with $0.50 \%$ (by volume) steel fibers, and MB3 - high strength concrete with $0.25 \%$ (by volume) steel fibers and $0.25 \%$ (by volume) basalt fibers. Dramix steel fibers with a length of $50 \mathrm{~mm}$ and a diameter of $1 \mathrm{~mm}$ and a tensile strength of $900 \mathrm{MPa}$ and a modulus of elasticity of $200 \mathrm{GPa}$ were used. Also, basalt fibers were used with an equal length of $50 \mathrm{~mm}$ and diameter of $0.02 \mathrm{~mm}$, tensile strength of $1680 \mathrm{MPa}$ and modulus of elasticity $89 \mathrm{GPa}$. Steel fibers had a hooked end with a 3D structure. Mixtures with the addition of fibers had an increased content of superplasticizer to $1.85 \%$ to obtain uniform consistency and to prevent the formation of compact fiber forms. After demoulding, the specimens were kept in a water bath at a temperature of $18+/-2^{\circ} \mathrm{C}$ until the start of the test. The concrete curing process lasted 28 days. In each test piece, a $3 \mathrm{~mm}$ wide and $30 \mathrm{~mm}$ deep primary notch was cut in the middle of the span using a circular saw. The dimensions of the test specimen, as well as the place of load application and support points are shown in Fig. 1. Altogether, eighteen beam specimens from each of the three series (MB1, MB2, MB3) were prepared: 3 test pieces not subjected to cyclic freeze/thaw, 3 test pieces frozen up to 150 cycles, 3 test pieces frozen up to 250 cycles, 3 test pieces frozen up to 350 cycles, 3 test pieces frozen up to 450 cycles, 3 test pieces intended for the initial estimation of the fracture strength. After each 50 freeze/thaw cycles, the changes of modulus of elasticity were checked using a non-destructive method. After another 100 cycles, starting from 150 freeze/thaw cycles, another 3 specimens were set aside for fracture mechanics parameter analysis. When the $D F$ value of all the series of tested concretes fell below $60 \%$, then the fracture mechanics parameters of the concretes were determined after 150, 250, 350 and 450 freeze/thaw cycles respectively 


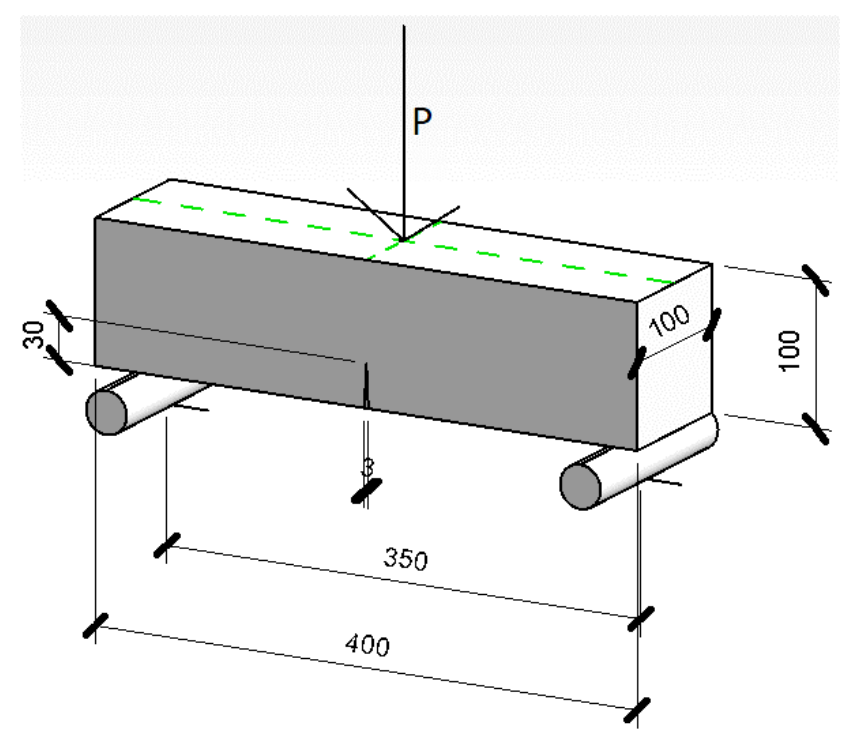

Fig. 1. The geometry of test specimens and the way of load application. Source: own research

\subsection{Test methodology}

Examination to determine fracture energy was carried out using the Zwick/Roell Z250 testing machine, based on RILEM TC 89-FMT [9] recommendations. The force was applied by controlled displacement of the piston to reach its maximum value after 5 minutes. The study was carried out under mode I of concrete fracture (tensile at bending) in a threepoint bending test. The value of fracture energy was determined based on the field under the diagram of the relation between the applied load and the deflection at the point of force application $(P-\delta)$ and the Eq. 1, proposed in [11].

$$
G_{F}=\frac{\int_{0}^{\delta} P(\delta) \mathrm{d} \delta+m g \delta}{\left(D-a_{0}\right) B}
$$

where: $\int_{0}^{\delta} P(\delta) \mathrm{d} \delta$ - field under the force-deflection diagram; $m$ - mass; $D$ - depth $(100 \mathrm{~mm})$; $B$ - width $(100 \mathrm{~mm}) ; a_{0}$ - deep of the initial notch $(30 \mathrm{~mm})$.

The fracture energy is a measure of the resistance of the material to brittle failure. The value of fracture energy consists of numerous causes, the most important of which are: surface energy, the energy of formation of new cracks, the energy of plastic deformation, energy related to fracture bridging, the energy of polymorphic transformation, the energy related to crack entanglement [12]. It is assumed that a crack propagates when the stress reaches a value exceeding the tensile strength of the given material at its tip and the further behavior of the material passes into the plastic area, as shown in Fig. 2. The measurement of the relationship $P-\delta$ was carried out until half of the maximum force of the specimen in the plastic state is reached. The evaluation of frost degradation of high-strength concretes was carried out using the ASTM C 666 methodology (Procedure B: rapid freezing in air and thawing in water) [8], which is used to determine the concrete durability index $D F$, according to the Eq. 2 


$$
D F=\frac{P N}{300} \cdot 100[\%]
$$

where: $N$-number of freeze/thaw cycles, $P$-relative value of dynamic modulus of elasticity.

Concrete is considered resistant to cyclic freeze/thaw when the $D F$ index is above $60 \%$. Determination of the HSC resonant frequencies was done with the Resonant Frequency Meter Controls C311-R. The frequency measuring station for $0,150,250,350$, and 450 freeze/thaw cycles is shown in Fig.3.

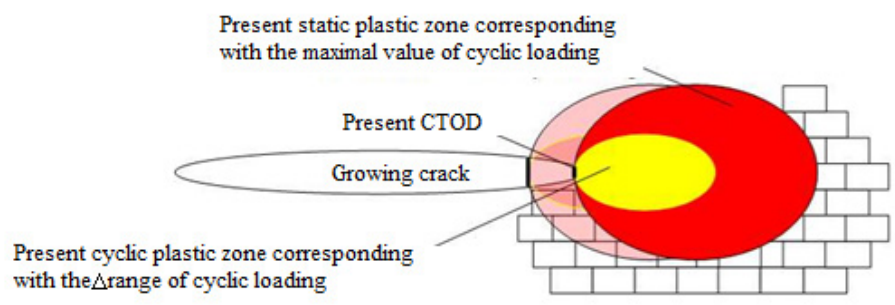

Fig. 2. Plastic zones before fracture Source: [13]
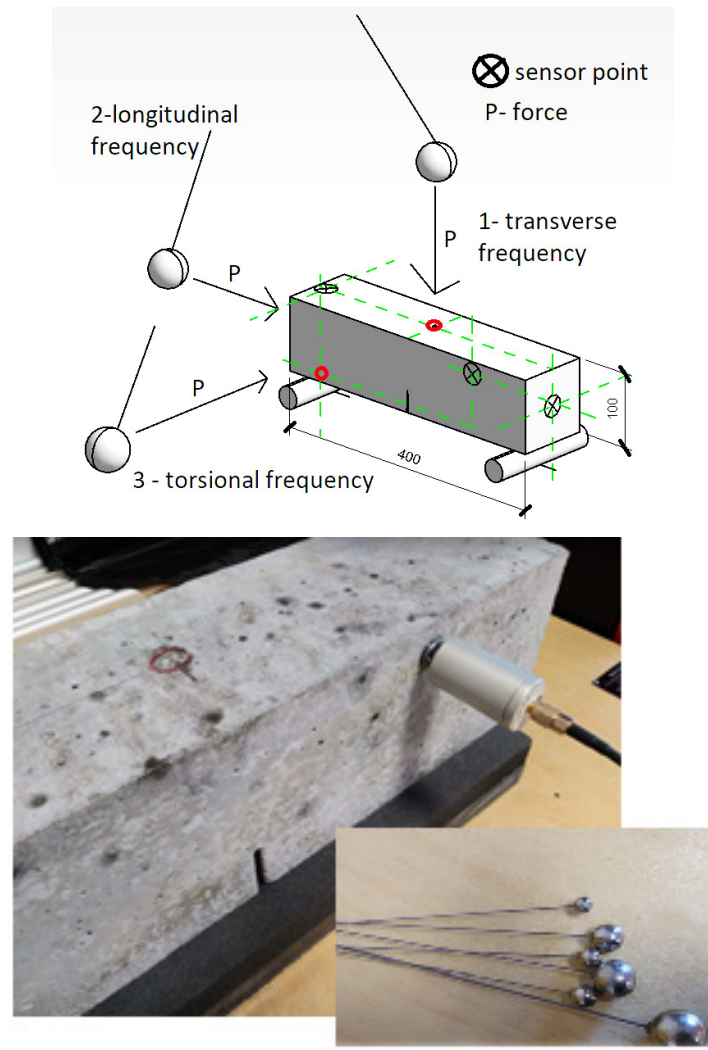

Fig. 3. Determination of the durability index according to ASTM C 666. Test sensor application points and dynamic actions. Source: own research 
Jenq and Shah [10] suggest measuring an additional diagnostic parameter $Q$ for concrete, which is of great importance for high-strength concretes. This parameter is a measure of concrete brittleness and depends on its modulus of longitudinal elasticity and characteristic fracture mechanics parameters: stress intensity factor $K_{\mathrm{IC}}$ and critical crack tip opening displacement $C T O D_{\text {c }}$, according to Eq. 3. It is believed that the higher the value of parameter $Q$, the lower the concrete brittleness.

$$
Q=\left(\frac{E \cdot C T O D_{c}}{K_{I C}}\right)^{2}
$$

where: $E$ - modulus of elasticity; $C T O D_{\mathrm{c}}$ - critical crack tip opening displacement; $K_{\mathrm{IC}}$ - critical value of stress intensity factor.

The analysis also determined the changes in the critical value of the release of potential energy $G_{\mathrm{IC}}$ as a result of cyclic freeze/thaw, according to Eq. 4, respectively in a flat deformation state. This value is directly related to the critical stress-intensity value of primary $K_{\mathrm{IC}}$, Young's E-modulus, and Poisson's factor, assumed for concrete of 0.2.

$$
G_{I C}=\frac{\left(1-v^{2}\right) K_{I C}}{E}
$$

where: $v$-Poisson's factor; $E$-Young's module; $K_{\mathrm{IC}}$ - the critical value of the stress intensity factor.

\section{Results and discussion}

The average values of longitudinal modulus of elasticity $E$, fracture energy $G_{\mathrm{F}}$, toughness index $Q$, and durability index $D F$ of concretes after 150, 250, 350, and 450 freeze/thaw cycles are presented in Tab. 1 . The loss of frost resistance described both by the $D F$ factor and a significant decrease in fracture energy values for HSC without fibers (MB1) and with steel fibers (MB2) occurred after 450 freeze/thaw cycles. The fracture energy for the MB1 series fell by more than $60 \%$ after 450 cycles compared to unfrozen concrete. The value of the durability index after 450 freeze/thaw cycles dropped to $16.12 \%$ and according to ASTM C 666 [8], when this index falls below $60 \%$, then the concrete loses its resistance to cyclic freeze/thaw. Concrete with steel fibers (MB2) after 450 freeze/thaw cycles was characterized by almost three times higher fracture energy than concrete without fibers (MB1). However, there is also a $45 \%$ decrease in fracture energy compared to non-frozen concrete and a low $D F$ value of $18.70 \%$. The addition of steel fibers to HSC leads to crack bridging when a fracture process develops in the concrete, despite the matrix-fiber boundary stratification. This mechanism contributes to an increase in the fracture energy value while propagating the internal defects in the concrete, which is reflected in the low $D F$ factor. In the case of concretes with mixed fibers (MB3), the loss of durability was observed already after 150 freeze/thaw cycles based on a decrease of $D F$ factor to $6.50 \%$. The presence of steel and basalt fibers with high tensile strength values contributed to the fact that, despite a very low $D F$ value, the fracture energy was higher than that of HSC after 450 freeze/thaw cycles without fibers when the frost resistance loss of this type of concrete was determined. The relatively low resistance of high-strength concretes with mixed steel and basalt fibers (MB3) to cyclic freeze/thaw described by $D F$ was due to a possible lack of adhesion of basalt fibers to the cement matrix. The concrete of the MB3 series has undergone numerous cracks and the aggregate has been separated from the cement matrix. In the case of concretes with steel fibers (MB2) and without fibers (MB1), an increase in the $D F$ factor became apparent between 150 and 250 freeze/thaw cycles. This 
Application of fracture energy for the assessment of frost degradation of high-strength concretes 63

is due to an increase in the strength of the concrete during the time before the loss of frost resistance and is shown in the analysis of fracture energy values at the very beginning of the test to 150 freeze/thaw cycle. It can be assumed that the loss of resistance to cyclic freeze/ thaw occurs when the energy associated with resisting crack growth decreases. Without added fibers, the change in fracture energy associated with the loss of cyclic freeze/thaw resistance was greater than $60 \%$. For HSC with steel fibers, it was greater than $45 \%$ and for mixed fibers, it was $30 \%$.

Table 1. Fracture mechanic parameters, brittleness parameter and durability factor determined on the basis of research. Source: own research

\begin{tabular}{|c|c|c|c|c|c|}
\hline Sample & $\begin{array}{l}\text { Number of freeze/thaw cycles } \\
n\end{array}$ & $\begin{array}{l}E \\
{[\mathrm{GPa}]}\end{array}$ & $\begin{array}{l}G F \\
{\left[\mathrm{Nm} / \mathrm{m}^{2}\right]}\end{array}$ & $\begin{array}{l}Q \\
{[\mathrm{~mm}]}\end{array}$ & $\begin{array}{l}D F \\
{[\%]}\end{array}$ \\
\hline $\begin{array}{l}\text { MB1 } \\
\text { fibreless }\end{array}$ & 0 & $45.73(0.90)^{*}$ & 15.01 & 210.47 & 100.00 \\
\hline $\begin{array}{l}\text { MB1 } \\
\text { fibreless }\end{array}$ & 150 & $45.23(0.33)^{*}$ & 35.93 & 189.59 & 50.04 \\
\hline $\begin{array}{l}\text { MB1 } \\
\text { fibreless }\end{array}$ & 250 & $45.80(0.45)^{*}$ & 20.16 & 190.45 & 83.67 \\
\hline $\begin{array}{l}\text { MB1 } \\
\text { fibreless }\end{array}$ & 350 & $45.63(0.53)^{*}$ & 19.89 & 190.31 & 70.68 \\
\hline $\begin{array}{l}\text { MB1 } \\
\text { fibreless }\end{array}$ & 450 & $8.10(0.32)^{*}$ & 5.85 & 190.93 & 16.12 \\
\hline $\begin{array}{l}\text { MB2 } \\
\text { with steel } \\
\text { fibers }\end{array}$ & 0 & $44.60(1.02)^{*}$ & 27.03 & 190.57 & 100.00 \\
\hline $\begin{array}{l}\text { MB2 } \\
\text { with steel } \\
\text { fibers }\end{array}$ & 150 & $43.87(0.68)^{*}$ & 41.16 & 189.57 & 48.53 \\
\hline $\begin{array}{l}\text { MB2 } \\
\text { with steel } \\
\text { fibers }\end{array}$ & 250 & $42.30(0.79)^{*}$ & 34.57 & 190.73 & 80.03 \\
\hline $\begin{array}{l}\text { MB2 } \\
\text { with steel } \\
\text { fibers }\end{array}$ & 350 & $43.60(1.06)^{*}$ & 18.64 & 191.50 & 68.40 \\
\hline $\begin{array}{l}\text { MB2 } \\
\text { with steel } \\
\text { fibers }\end{array}$ & 450 & $9.30(2.59)^{*}$ & 14.73 & 190.76 & 18.70 \\
\hline $\begin{array}{l}\text { MB3 } \\
\text { with mixed } \\
\text { fibers }\end{array}$ & 0 & $48.27(2.59)^{*}$ & 35.67 & 192.00 & 100.0 \\
\hline $\begin{array}{l}\text { MB3 } \\
\text { with mixed } \\
\text { fibers }\end{array}$ & 150 & $3.50(1.07)^{*}$ & 23.57 & 182.00 & 6.46 \\
\hline
\end{tabular}

The improvement of frost resistance of HSC described by durability factor $D F$ analysis based on ASTM C666A method by adding $0.10 \%$ (by volume) polypropylene fibers is presented in [14]. The decrease in $D F$ index below $60 \%$ HSC with fibers occurred after about 460 freeze/thaw cycles, while without fiber addition, concrete with $80 \mathrm{MPa}$ compressive strength lost its frost resistance after 390 cycles. During the study of frost resistance of high-strength concrete with the addition of $0.5 \%$ steel fibers analysed in [15] by weight loss 
and decrease in compressive strength after cyclic freeze/thaw, the loss of frost resistance was already noted after 100 freeze/thaw cycles in the case of no air-entraining and freezing in water. In the case of air-entrained concrete mix and freezing in air, no significant decrease in weight and compressive strength was observed after 100 cycles. In the analysis [16] of the high-performance concrete with steel fibers and mineral additives, after a period of 300 freeze/thaw cycles, the relative elastic modulus was $85.7 \%$, indicating that the concrete did not undergo significant frost degradation during the test period. Analyzing the frost resistance of ultrahigh-strength concretes with the addition of $1 \%$ steel fibers, it was found that after 180 freeze/ thaw cycles, with a $D F$ factor of $89 \%$, there was a significant reduction in the weight of the concrete specimens $(>7.14 \%$ ), which was due to the difficulty in proper fiber placement [17].

The parameter $Q$ describing the brittleness of concrete indicates a slight influence of the addition of steel fibers and a mixture of steel and basalt fibers in the amount of $0.5 \%$ on the brittleness. In order to observe the change in concrete characteristics from quasi-brittle to quasi-plastic, the fiber addition in the mixture should be greater. Also, cyclic freeze/thaw did not significantly change the $Q$ parameter.

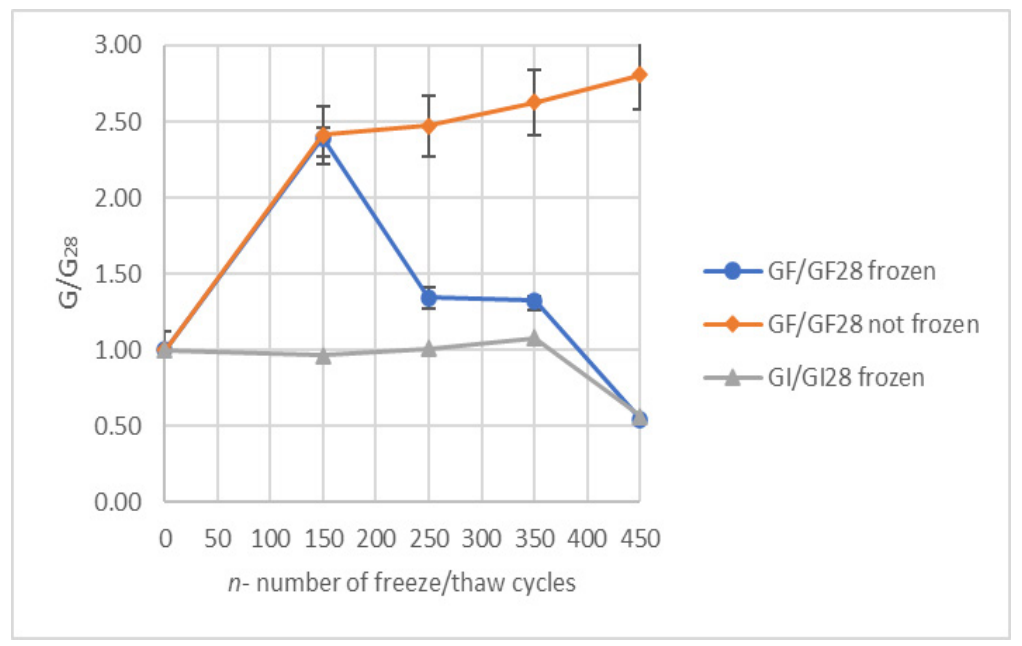

Fig. 4. Changes in fracture energy $G_{\mathrm{F}}$ and critical energy release $G_{\mathrm{I}}$ after $n$ freeze/thaw cycles for MB1 series concretes. A description of the designations is included in the text. Source: own research 


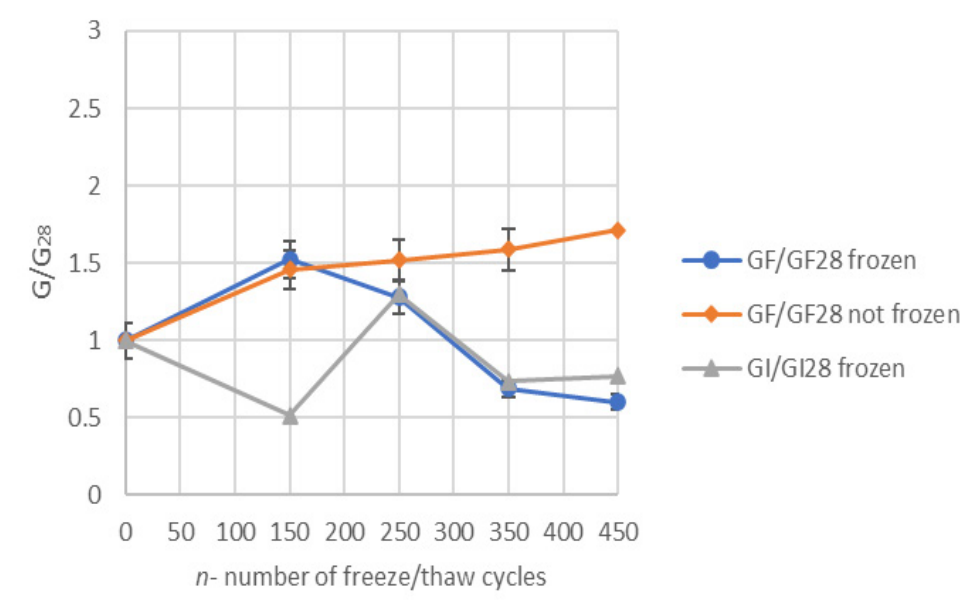

Fig. 5. Changes in fracture energy and critical energy $G_{\mathrm{F}}$ and critical energy release $G_{\mathrm{I}}$ after $n$ freeze/thaw cycles for MB2 series concretes. A description of the designations is provided in the text. Source: own research

Figs 4-6 show an analysis of changes in fracture energy values versus the number of freeze/thaw cycles to concretes tested after 28 days of curing and concretes not subjected to freeze/thaw cycles. Changes in the critical release of $G_{\text {IC }}$ energy release in flat deformation state after 150, 250, 350, 450 freeze/thaw cycles were also determined. The markings in the diagrams are respectively: $G_{\mathrm{F}} / G_{\mathrm{F} 28}$ frozen - change of fracture energy of frozen concrete after $n$ freeze/thaw cycles compared to fracture energy after 28 days of curing of unfrozen concrete; $G_{\mathrm{F}} / G_{\mathrm{F} 28}$ not frozen - change of fracture energy of unfrozen concrete after $n$ freeze/thaw cycles to fracture energy after 28 days of curing of unfrozen concrete; $G_{I} / G_{\text {I28 }}$ - change of the rate of fracture energy release of unfrozen concrete after $n$ freeze/thaw cycles to unfrozen concrete after 28 days of curing. Up to 150 freeze/thaw cycles, a homogeneous increase of fracture energy of frozen and unfrozen concretes is visible for both HSC without fibers (MB1), were $G_{\mathrm{F}} / G_{\mathrm{F} 28}=2.42$ as well as HSC with steel fibers (MB2), where $G_{\mathrm{F}} / G_{\mathrm{F} 28}=1.51$. Concrete with mixed, steel, and basalt fibers (MB3) has been characterized by decreased fracture energy up to $34 \%$ after 150 freeze/thaw cycles since the beginning of the cycle. Concrete of the MB3 series not subjected to cyclic freeze/thaw with an increase in strength over time is characterized by an increase in fracture energy up to $67 \%$ after a period equal to 150 freeze/ thaw cycles (50 days). The critical rate of energy release of fibreless concrete is constant up to 350 freeze/thaw cycles, followed by a sudden drop. This indicates the hardly predictable characteristics of high-strength concrete material, which changes its properties. In the case of HSC with steel fibers, an alternating increase and decrease in the critical rate of energy release in subsequent freeze/thaw cycles is noticeable, due to the presence of bridging fibre scratches. In the MB3 series, up to 50 freeze/thaw cycles, there is a sharp $89 \%$ drop in the energy release rate, followed by a constant value until the end of the test 


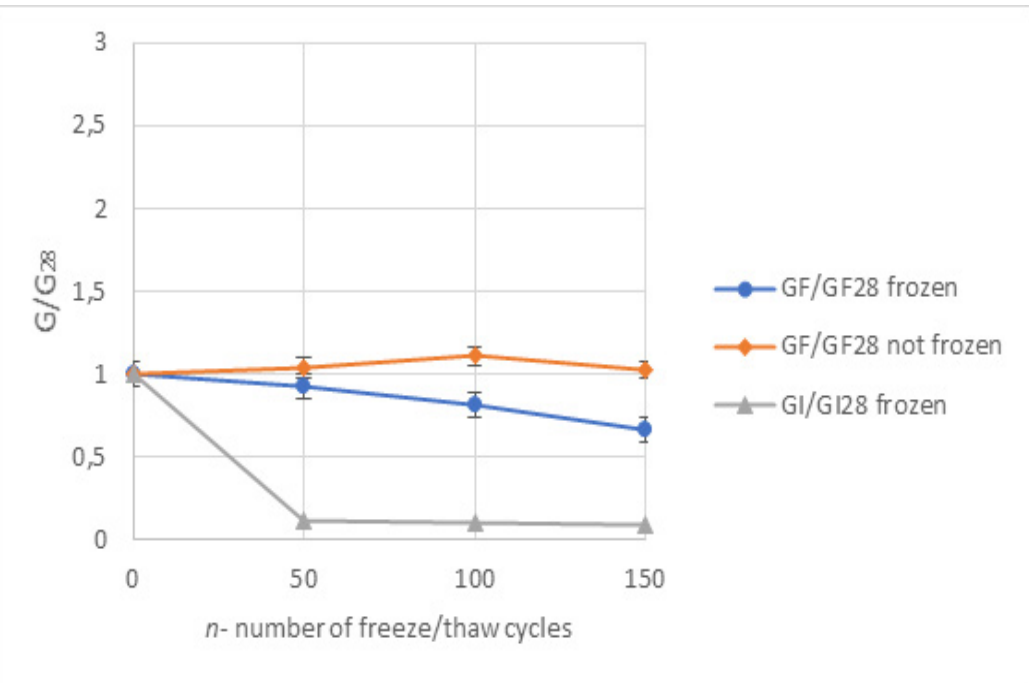

Fig. 6. Changes in fracture energy $G_{\mathrm{F}}$ and critical energy release $G_{\mathrm{I}}$ after $n$ freeze/thaw cycles for MB3 series concretes. A description of the designations is provided in the text. Source: own research

\section{Conclusions}

The frost degradation of high-strength concretes, assessed on the basis of changes in fracture energy values, made it possible to obtain a more accurate description than in the case of classical methods of processes taking place in concrete as a result of cyclic freeze/thaw. Analyses using the parameters of fracture mechanics of concrete structures exposed to the destructive external environment show the progress of propagation of initial discontinuities and internal cracks - the cyclic freeze/thaw of high-strength concrete results in a significant reduction of fracture energy. As frost degradation progresses, the rate of release of the energy required for crack growth is reduced. The addition of $0.5 \%$ of steel fibers to high-strength concrete results in a slight improvement in the mechanical characteristics of the degraded material but does not significantly increase its durability under cyclic freeze/thaw conditions. The loss of adhesion of basalt fibers to the cement matrix leads to a reduction in frost resistance of high strength concrete. Cyclic freeze/thaw, as well as the presence of $0.5 \%$ of fibers (steel and basalt), did not significantly change the parameter describing concrete brittleness $Q$. Research should be continued on the fiber content in HSC, which would have a decisive influence on the improvement of fracture mechanics and durability parameters.

\section{References}

[1] Golewski G., Sadowski T., "The parameters of concrete fracture mechanics are determined on the basis of experimental tests according to the I crack model", Construction Review, no. 7-8, (2005), pp. 28-33.

[2] Smith G.J., Rad F.N., "Economic Advantages of High-Strength Concretes in Columns", Concrete International, vol. 11, no. 4, (1989), pp. 37-43.

[3] Jóźwiak - Niedźwiedzka D., "Preventing peeling of concrete surfaces with the use of moistened drug aggregate", Roads and Bridges, no. 2, (2006), pp. 37-54. 
[4] Cheng Y., Zhang Y., Jiao Y., "Quantitative analysis of concrete property under effects of crack, freeze-thaw and carbonation", Construction Building Materials, no. 129, (2016), pp. 106-115. https://doi.org/10.1016/j.conbuildmat.2016.10.113

[5] Song P.S., "Mechanical properties of high - strength steel fiber reinforced concrete", Construction and Building Materials, vol. 18, no. 9, (2004), pp. 669-73.

[6] Holschemacher K., Mueller T., Ribakov Y., "Effect of steel fibres on mechanical properties of high - strength concrete", Materials and design, no. 31, (2010), pp. 2604-2615. https://doi.org/10.1016/j. matdes.2009.11.025

[7] Kosior- Kazberuk M., "Variations in fracture energy of concrete subjected to cyclic freezing and thawing", Civil and Mechanical Engineering, no.13, (2013), pp. 254-259. https://doi.org/10.1016/j. acme.2013.01.002

[8] ASTM C 666: 2008 Standard Test Method for Resistance of Concrete to Rapid Freezing and Thawing.

[9] Shah S.P., "Size - effect method for determining fracture energy and process zone size of concrete, RILEM TC 89-FMT", Materials and Structures, no. 23, (1990),pp. 461-465.

[10] Jenq Y.S., Shah S.P., “A two parameter fracture model for concrete”, Journal of Engineering Mechanics, no. 111, (1985), pp. 1227-1241.

[11] Elices M, Guinea G, Planas J., "Measurement of the fracture energy using three-point bend tests: part 3 - influence of cutting the P- $\delta$ tail", Material Structures, vol. 25, no. 6, (1992), pp.327-34.

[12] Neimitz A., Mechanika pękania, PWN, Warszawa 1998.

[13] Lesiuk G., "Application of a New, Energy-Based $\Delta S^{*}$ Crack Driving Force for Fatique Crack Growth Rate Description”, Materials, no. 12, (2019), pp. 1-13. https://doi.org/10.3390/ma12030518

[14] Ma H., Yu H., Li C., Tan Y., Cao W., Da B., "Freeze-thaw damage to high- preformance concrete with synthetic fibre and fly ash due to ethylene glycol deicer", Construction and Building Materials, no. 187, (2018), pp. 197-204. https://doi.org/10.1016/j.conbuildmat.2018.07.189

[15] Wawrzeńczyk J., Molendowska A., Kłak A., "Frost durability of steel fiber self-compacting concrete for pavements", The Baltic Journal of Road and Bridge Engineering, vol. 11, no. 1, (2016), pp. 35-42. https://doi.org/10.1088/1757-899X/471/3/032023

[16] Lee, J.S., "Properties on the Freeze-Thaw Resistance of High Performance Concrete Using Fibers and Mineral Admixtures", Materials Science Forum, vol. 893, (2017), pp. 375-379. https://doi. org/10.4028/www.scientific.net/MSF.893.375

[17] Smarzewski P., Barnat-Hunek D., "Effect of fiber Hybridization on durability Related Properties of Ultra-High Performance Concrete", International Journal of Concrete Structures and Materials, vol. 11, no. 2, (2017), pp. 315-325. https://doi.org/10.1007/s40069-017-0195-6 
